\title{
Increased accumulation of hypoxia-inducible factor- $1 \alpha$ with reduced transcriptional activity mediates the antitumor effect of triptolide
}

Zhao-Li Zhou ${ }^{1,4+}$, Zhi-Guo Luo ${ }^{3 \dagger}$, Bing Yu' ${ }^{1}$, Yi Jiang ${ }^{1}$, Yi Chen ${ }^{1}$, Jian-Ming Feng ${ }^{1}$, Mei Dai ${ }^{1}$, Lin-Jiang Tong ${ }^{1}$, Zheng $\mathrm{Li}^{2}$, Yuan-Chao Li ${ }^{2}$, Jian Ding ${ }^{1}$, Ze-Hong Miao ${ }^{1 *}$

\begin{abstract}
Background: Hypoxia-inducible factor- $1 \alpha$ (HIF-1 $\alpha$ ), a critical transcription factor to reduced $\mathrm{O}_{2}$ availability, has been demonstrated to be extensively involved in tumor survival, aggressive progression, drug resistance and angiogenesis. Thus it has been considered as a potential anticancer target. Triptolide is the main principle responsible for the biological activities of the Traditional Chinese Medicine tripterygium wilfordii Hook F. Triptolide possesses great chemotherapy potential for cancer with its broad-spectrum anticancer, antiangiogenesis, and drugresistance circumvention activities. Numerous biological molecules inhibited by triptolide have been viewed as its possible targets. However, the anticancer action mechanisms of triptolide remains to be further investigated. Here we used human ovarian SKOV-3 cancer cells as a model to probe the effect of triptolide on HIF-1 $\alpha$.

Results: Triptolide was observed to inhibit the proliferation of SKOV-3 cells, and meanwhile, to enhance the accumulation of HIF-1 $\alpha$ protein in SKOV-3, A549 and DU145 cells under different conditions. Triptolide did not change the kinetics or nuclear localization of HIF-1 $\alpha$ protein or the $26 \mathrm{~S}$ proteasome activity in SKOV-3 cells. However, triptolide was found to increase the levels of HIF-1 $\alpha$ mRNA. Unexpectedly, the HIF-1 $\alpha$ protein induced by triptolide appeared to lose its transcriptional activity, as evidenced by the decreased mRNA levels of its target genes including VEGF, BNIP3 and CAIX. The results were further strengthened by the lowered secretion of VEGF protein, the reduced sprout outgrowth from the rat aorta rings and the inhibitory expression of the hypoxia responsive element-driven luciferase reporter gene. Moreover, the silencing of HIF-1 $\alpha$ partially prevented the cytotoxicity and apoptosis triggered by triptolide.

Conclusions: The potent induction of HIF-1 $\alpha$ protein involved in its cytotoxicity, together with the suppression of HIF-1 transcriptional activity, indicates the great therapeutic potential of triptolide as an anticancer drug. Meanwhile, our data further stress the possibility that HIF-1 $\alpha$ functions in an unresolved nature or condition.
\end{abstract}

\section{Background}

Hypoxia-inducible factor- $1 \alpha$ (HIF- $1 \alpha)$ is a critical transcription factor responsible for adaptive responses of cancer cells to reduced $\mathrm{O}_{2}$ availability [1]. Through modulation of the expression of at least 70 genes, HIF$1 \alpha$ is extensively involved in tumor survival, aggressive progression, drug resistance and angiogenesis [2].

\footnotetext{
*Correspondence: zhmiao@mail.shcnc.ac.cn

+ Contributed equally

'Division of Antitumor Pharmacology, State Key Laboratory of Drug Research, Shanghai Institute of Materia Medica, Chinese Academy of

Sciences, Shanghai 201203, China

Full list of author information is available at the end of the article
}

Elevated levels of HIF-1 $\alpha$ protein are observed in various human primary and metastatic cancers, either as direct results of intratumoral hypoxia or secondary to genetic alterations in oncogenes or tumor suppressor genes $[3,4]$. Those cancers are generally relatively poorly responsive to chemotherapy or radiotherapy with poor prognosis [5]. Thus, HIF-1 $\alpha$ has been proposed as a promising anticancer target [6]. On the other hand, HIF-1 $\alpha(-/-)$ tumors have also been demonstrated to show a feature of faster proliferation and more obvious resistance to apoptosis than the HIF- $1 \alpha(+/+)$ counterparts [7], suggesting a possibility that HIF-1 $\alpha$ may have unknown function(s) or exert its transcriptional activity 
dependent on specific, undefined conditions or stimulations.

Triptolide is an effective principle of the Traditional Chinese Medicine tripterygium wilfordii Hook F that has been used to treat autoimmune and inflammatory diseases for centuries $[8,9]$. Triptolide possesses broadspectrum anticancer, antiangiogenesis, and drugresistance circumvention activities [10-13]. Moreover, our recent study shows that a novel C14-hydroxyl substituted triptolide derivative elicits selective anticancer effects, specifically against ovarian and prostate cancers in nude mice xenograft models, with reduced toxicity as compared to the parent triptolide [14]. Nevertheless, the anticancer action mechanisms of triptolide are complicated and remain to be further investigated. Triptolide downregulates various proteins including heat shock protein 70 , Bcr-Abl, survivin, Mcl-1, Akt, c-myc, cyclin $\mathrm{A} / \mathrm{cdk} 2$, cyclin $\mathrm{B} / \mathrm{cdc} 2$, cyclin $\mathrm{D} 1$ and $\mathrm{pRB}$, which may contribute to its anticancer activity under specific conditions $[12,15,16]$. In addition, inhibition of nuclear factor $\kappa \mathrm{B}$ activation by triptolide is also assoctiated with its potentiation of TNF related apoptosis-inducing ligandinduced anticancer effects [17]. Notably, however, triptolide enhances the levels of p53 protein in p53-wild type human tumors but lowers its transcriptional activity, resulting in the reduced expression of $\mathrm{p} 21$ protein [18-20].

Based on the discovery of selective anticancer activity of the new triptolide analogue in human ovarian and prostate cancer xenograft models [14], in this current study, we used human ovarian SKOV-3 cancer cells as a model to further investigate the mechanisms of action of triptolide. Triptolide was unexpectedly revealed to enhance the cellular accumulation of HIF- $1 \alpha$ protein with reduced transcriptional activity. The impact of triptolide on HIF- $1 \alpha$ contributes to its partial anticancer effect. These results from triptolide further stress the possibility that HIF- $1 \alpha$ functions in an unresolved nature or condition.

\section{Results}

Triptolide elicits cytotoxicity and increases HIF- $1 \alpha$ accumulation

Triptolide has been demonstrated to possess potent antitumor and antiangiogenic activities [12,21]. HIF-1 $\alpha$ is an important regulator of tumor angiogenesis [22]. To find a proper model to examine the effect of triptolide on HIF- $1 \alpha$ protein, we first tested the sensitivity of human ovarian cancer SKOV-3 cells to this compound because the cells are highly sensitive, both in vitro and in vivo, to triptolide analogues [14].

As expected, triptolide elicited potent concentrationdependent cytotoxicity in SKOV-3 cells with an averaged $\mathrm{IC}_{50}$ value of $10.24 \mathrm{nM}$ for 72 -h treatments (Fig. 1A).
Unexpectedly, however, triptolide led to significant accumulation of cellular HIF- $1 \alpha$ protein in a concentrationdependent manner following the 12-h exposure of SKOV-3 cells at normoxia (Fig. 1B). The similar results were reproducible in SKOV-3 cells exposed to hypoxia or mimic hypoxia with cobalt chloride $\left(\mathrm{CoCl}_{2}\right)$ [23] (Fig. 1B) or in hypoxic human lung A549 and prostate DU145 cancer cells (Fig. 1C and 1D). The data indicate that the increase in the cellular accumulation of HIF- $1 \alpha$ protein by triptolide is independent of the environmental oxygen pressure and the cell type, suggesting that it is an inherent capability of this agent.

To function as a transcription factor, HIF- $1 \alpha$ heterodimerizes HIF-1 $\beta$ that is constitutively expressed [2]. The treatment with triptolide did not change the levels of HIF-1 $\beta$ in normoxic, hypoxic or $\mathrm{CoCl}_{2}$-treated SKOV-3 cells (Fig. 1B). Moreover, co-immunoprecipitation further showed that triptolide did not impair the binding of HIF- $1 \alpha$ to HIF- $1 \beta$ (Fig. 1E). In addition, triptolide just marginally changed the levels of HIF- $2 \alpha$ (Fig. 1F), another hypoxia-inducible factor (HIF) alpha subunit that has various overlapped targeting genes with HIF- $1 \alpha$ [24].

Triptolide increases HIF-1 $\alpha$ accumulation but does not change its kinetics and cellular localization at hypoxia In response to acute hypoxia, HIF- $1 \alpha$ protein rapidly accumulates in the cells due to the inactivation of oxygen-sensitive prolyl hydroxylase [25]; but prolonged hypoxia initiates CHIP (a prolyl hydroxylase -independent E3 ligase) -mediated HIF-1 $\alpha$ degradation and lowers its cellular levels [26]. This typical first-up-and-thendown kinetics of HIF- $1 \alpha$ protein also occurred in SKOV-3 cells at hypoxia (Fig. 2A and 2B). To clarify whether triptolide affects such kinetics, we exposed hypoxic SKOV-3 cells to this compound. The result showed that triptolide, though increasing the amount at each corresponding time-point, did not change the kinetic trend of the accumulation and degradation of HIF-1 $\alpha$ protein (Fig. $2 \mathrm{~A}$ and $2 \mathrm{~B}$ ). Moreover, HIF- $1 \alpha$ protein was also localized in the nuclei of the hypoxic SKOV-3 cells treated with triptolide (Fig. 2C), just as generally expected $[27,28]$. These data critically suggest that triptolide may not interfere with HIF- $1 \alpha$ protein degradation, either oxygen-dependent or oxygen-independent, when collectively considering the increased levels of HIF-1 $\alpha$ protein at normoxia (Fig. 1B).

\section{Triptolide does not affect the $26 \mathrm{~S}$ proteasome activity but enhances the levels of HIF-1 $\alpha$ mRNA}

To validate the effect of triptolide on HIF-1 $\alpha$ protein degradation, we detected whether triptolide inhibited the activity of $26 \mathrm{~S}$ proteasome, which is crucial degradation machinery for HIF-1 $\alpha$ protein [29]. Triptolide 


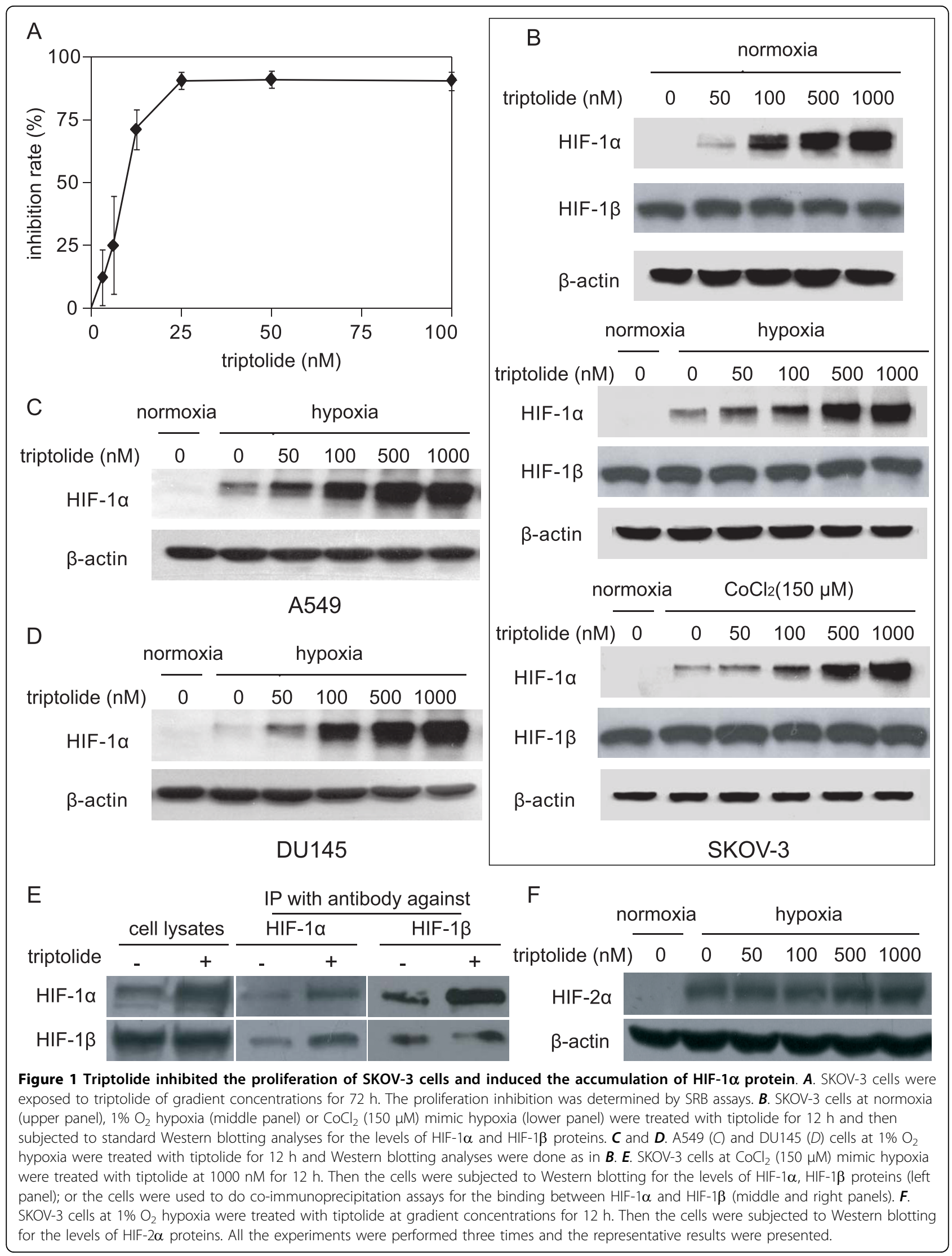




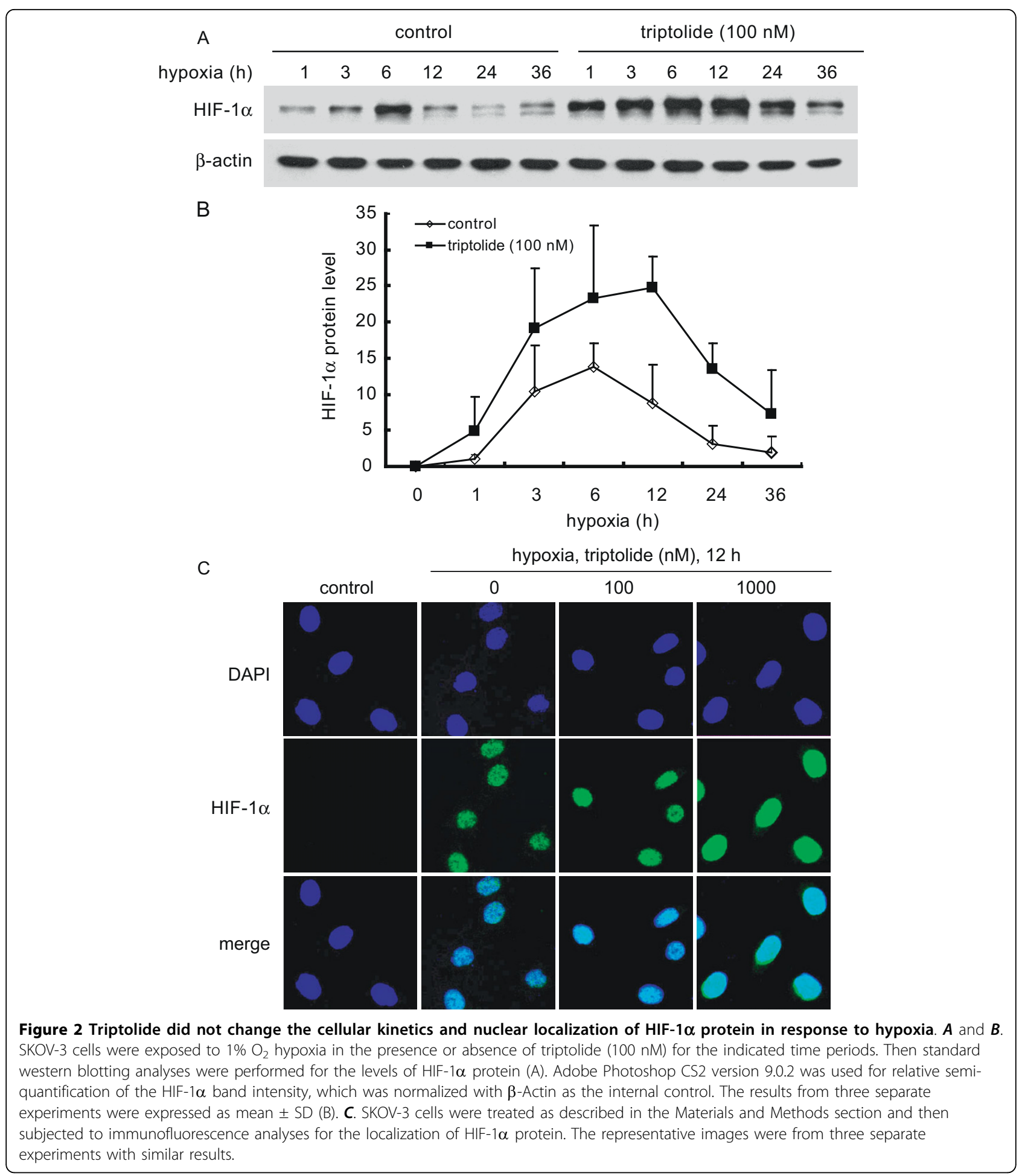

was not shown to apparently inhibit the chymotrypsinlike activity of $26 \mathrm{~S}$ proteasome in either SKOV-3 cells or their cell lysates treated with triptolide, even up to $10000 \mathrm{nM}$. In contrast, the positive control MG132 dramatically inhibited the $26 \mathrm{~S}$ proteasome activity (Fig. 3A and $3 \mathrm{~B})$.
To further dissect the possible cause of HIF-1 $\alpha$ induction by triptolide, we used semi-quantitative RT-PCR and quantitative real-time PCR assays for the levels of HIF- $1 \alpha$ mRNA in the triptolide-treated SKOV-3 cells. The results showed that triptolide enhanced the levels of HIF-1 $\alpha$ mRNA in a concentration-dependent manner 


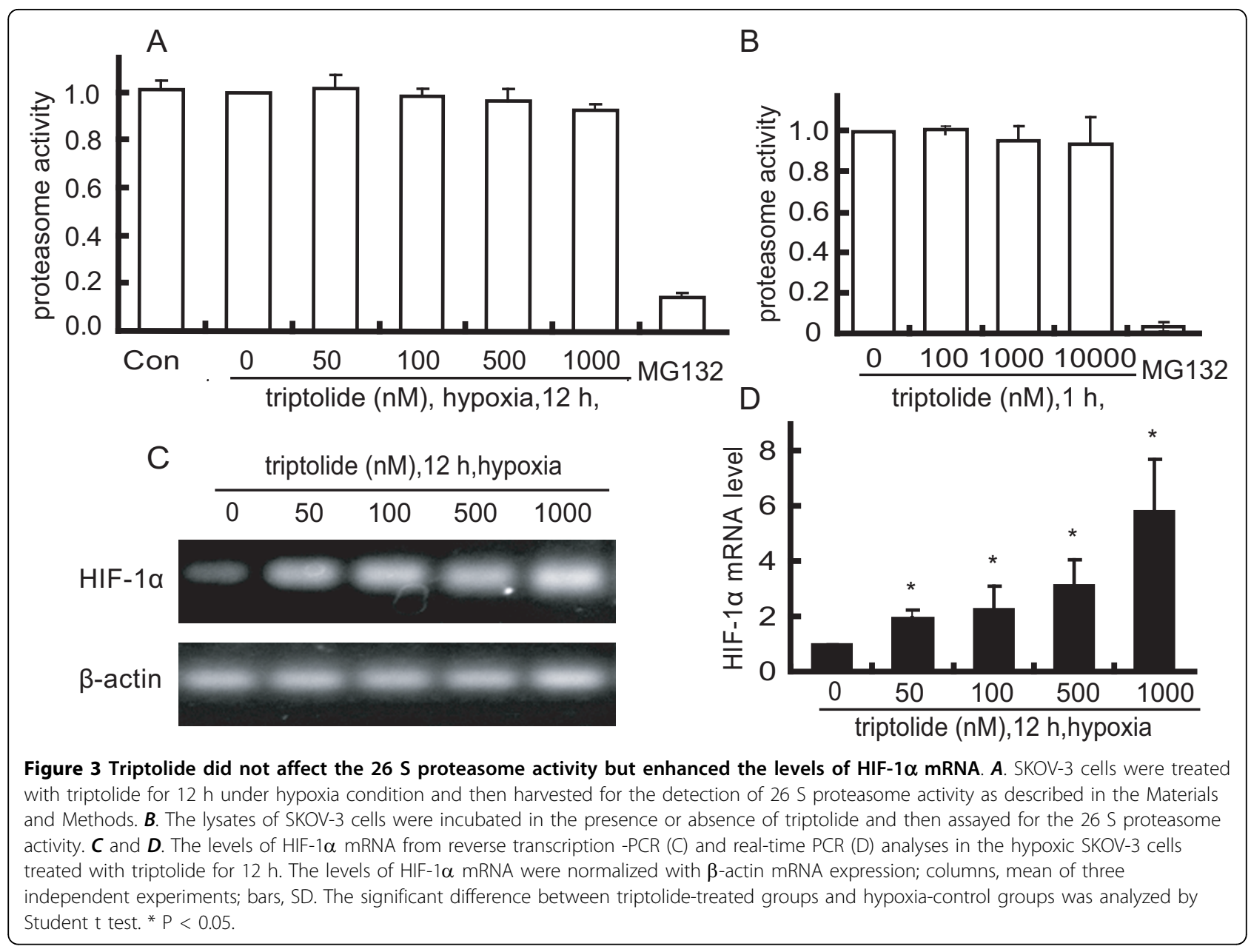

(Fig. 3C and 3D), which may be responsible for the HIF- $1 \alpha$ accumulation.

\section{Triptolide reduces the transcriptional activity of HIF-1 $\alpha$ protein}

HIF- $1 \alpha$ protein functions as a critical transcription factor in adaptive response to hypoxia [1]. To determine whether triptolide also increases the transcriptional activity of HIF- $1 \alpha$ protein when enhancing its accumulation, we examined the expression levels of its several target genes including vascular endothelial growth factor (VEGF), BCL2 and adenovirus E1B 19-kDa-interacting protein 3 (BNIP3) and carbonic anhydrase IX (CAIX) $[30,31]$ in the triptolide-treated SKOV-3 cells. Unexpectedly, however, the results revealed that the mRNA levels of the three genes did not increase but decreased typically in a concentration-dependent manner (Fig. 4A). Moreover, the secretion of VEGF protein, a critical angiogenesis factor, also reduced (Fig. 4B). Triptolide was further revealed to obviously inhibit the sprout outgrowth from the rat aorta rings (Fig. 4C), indicating its antiangiogenesis capability as previously reported $[10,11,21]$.

To confirm whether triptolide reduces the transcriptional activity of HIF-1 $\alpha$ protein, we used the hypoxia responsive element (HRE)-driven luciferase reporter gene assays. After failure with SKOV-3 or A549 cells due to the low transfection efficiency, we co-transfected the HRE luciferase reporter plasmid and the renilla luciferase reporter vector pGL-3 into MCF-7 cells for $24 \mathrm{~h}$. Then the cells were treated with triptolide for additional $12 \mathrm{~h}$. Triptolide reduced the luciferase-elicited fluorescence in a concentration-dependent fashion, and at $1000 \mathrm{nM}$ of triptolide, the fluorescence almost lowered to the basal level (Fig. 4D). Collectively, the above evidence arising from all the levels of the transcription of the target genes, the reporter gene and the subsequent biological effects indicates that triptolide, though increasing the cellular accumulation of HIF- $1 \alpha$ protein, reduces its transcriptional function. 


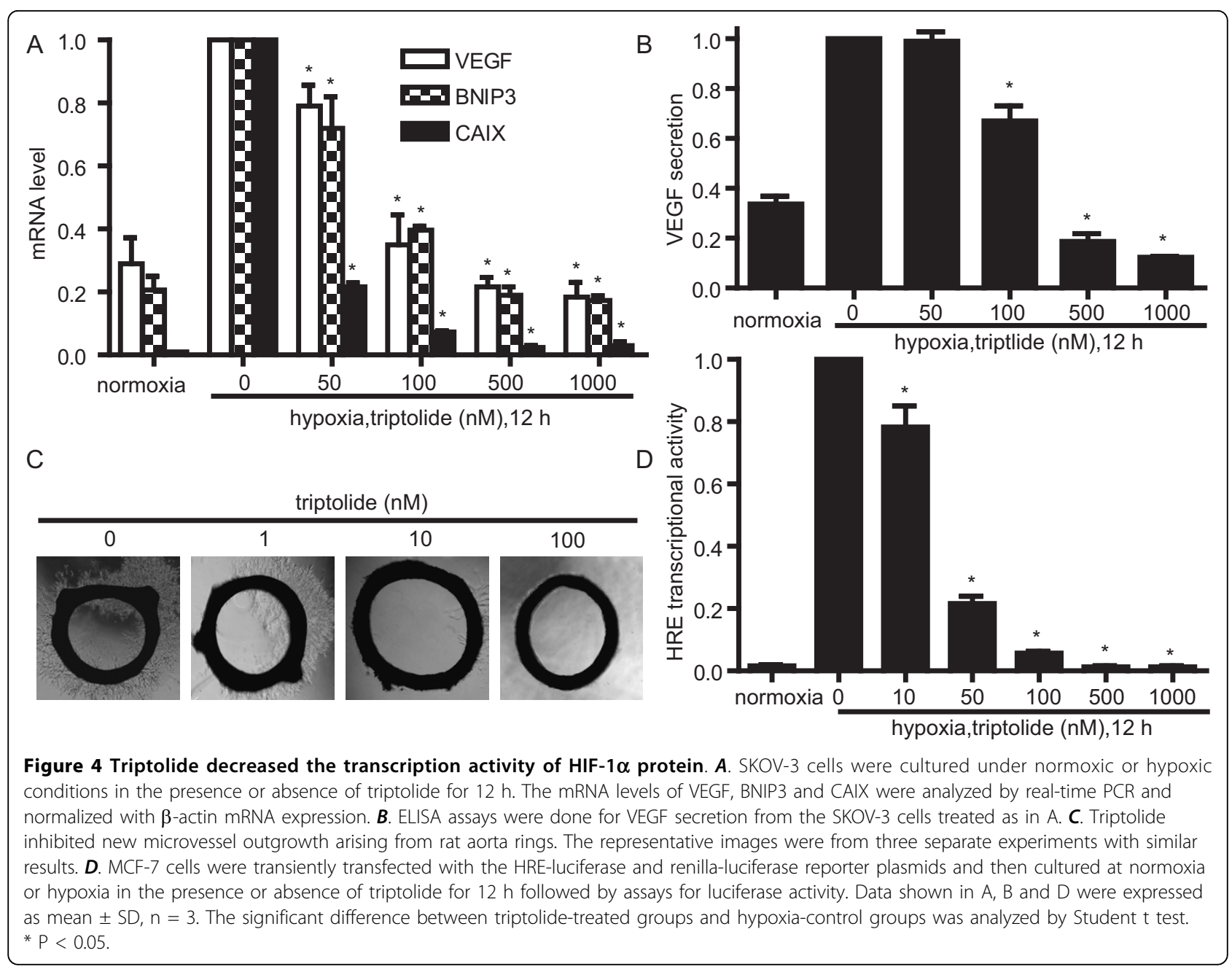

The action of triptolide on HIF- $1 \alpha$ contributes at least partially to its anticancer activity

To demonstrate whether the effect of triptolide on HIF$1 \alpha$ is associated with its anticancer activity, we knocked down HIF-1 $\alpha$ with three specific HIF-1 $\alpha$ siRNAs in SKOV-3 cells (Fig. 5A). SRB assays showed that the silencing of HIF-1 $\alpha$ partially prevented the cytotoxicity of triptolide (Fig. 5B). Consistently, triptolide induced much less apoptosis in the HIF-1 $\alpha$-silenced cells than in the control cells (Fig. 5C and 5D). These data clearly reveal a close association of the effect of triptolide on HIF-1 $\alpha$ with its anticancer activity.

\section{Discussion}

Overexpression of HIF- $1 \alpha$ in human cancers is usually correlated with poor prognosis and poor therapeutic response [32]. HIF-1 $\alpha$ has been considered as a potential therapeutic target [33]. Nevertheless, there are also reports that HIF-1 $\alpha$ null tumors grow unexpectedly fast, and that tumor cells with HIF-1 $\alpha(-/-)$ tumors are more proliferative and less apoptotic than those with HIF-1 $\alpha$
$(+/+)$ even when tumor vessel formation was impaired [7]. These paradoxical observations seem to suggest that the roles of HIF-1 $\alpha$ in tumor development and/or in cancer therapy are conditional and that the conditions remain to be further clarified so that this important tumor-related factor can be better employed. Our findings in this current study further stress such conditional or stimulation-dependnent changes as the potent anticancer agent triptolide has been revealed to increase the cellular accumulation of HIF-1 $\alpha$ protein that contributes partially to its anticancer activity.

Triptolide has been well documented to possess potent, broad-spectrum antitumor activity and to inhibit angiogenesis $[10,34]$. Our present study showed that triptolide enhanced the cellular accumulation of HIF-1 $\alpha$ protein in SKOV-3, A549 and DU145 cancer cells at normoxia, hypoxia or $\mathrm{CoCl}_{2}$-mimic hypoxia. However, triptolide did not apparently change the protein levels of HIF-1 $\beta$ and HIF- $2 \alpha$ and the binding of HIF- $1 \alpha$ to HIF- $1 \beta$. Triptolide did not change the kinetics or localization of HIF-1 $\alpha$ protein in SKOV-3 cells exposed to hypoxia. Consistently, 


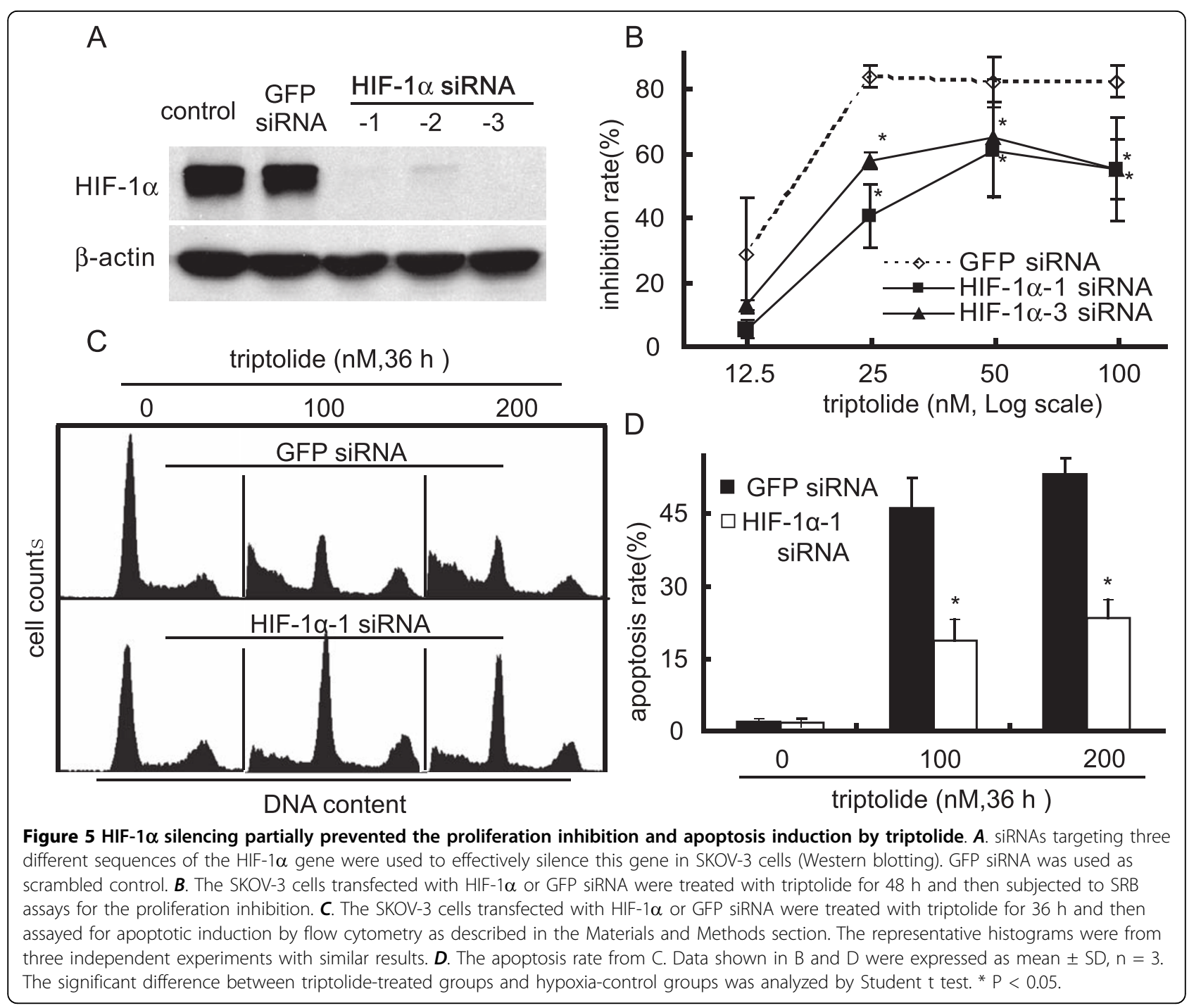

triptolide did not impair the $26 \mathrm{~S}$ proteasome activity. The increased levels of HIF-1 $\alpha$ mRNA could be responsible for the accumulation of HIF- $1 \alpha$ protein induced by triptolide in SKOV-3 cells. Unexpectedly, the triptolide-increased HIF- $1 \alpha$ protein seems to lose its transcriptional activity, as evidenced by the decreased mRNA levels of its target genes including VEGF, BNIP3 and CAIX (the transcription of which is generally promoted by HIF-1 $\alpha$ [30,31]). The results were further strengthened by the lowered secretion of VEGF protein, the reduced sprout outgrowth from the rat aorta rings and the inhibitory expression of the HRE luciferase reporter gene. More importantly, the partial prevention of cytotoxicity and apoptotic induction of triptolide by HIF- $1 \alpha$ silencing indicates the contribution of the accumulated HIF-1 $\alpha$ protein to the anticancer action of this compound.

Several important points arise from those results: (1) The apparent association of the increased HIF- $1 \alpha$ protein induced by triptolide with its anticancer activity challenges the general notion that the downregulation of HIF- $1 \alpha$ protein elicits anticancer and antiangiogenic effects, as many HIF-1 $\alpha$ inhibitors do [35,36]. (2) The HIF-1 $\alpha$ protein in the triptolide-treated cells appears to have some additional non-transcriptional function because it loses its transcriptional activity but is indeed involved in the anticancer and antiangiogenic actvity of triptolide in our case. Another possibility is that the apparently decreased transcriptional activity of the triptolide-induced HIF- $1 \alpha$ protein may be subsequent to the inhibitory effect of triptolide on RNA polymerase II (RNA Pol II). As a critical general transcription factor, RNA Pol II has been demonstrated to be inhibited by triptolide, which could contribute to its global transcriptional arrest [37,38]. The inhibition of RNA Pol II impairs the transcription-promoting function of HIF-1, thus reducing the transcriptional activity of the triptolideinduced HIF- $1 \alpha$ protein. Actually, triptolide has been 
reported to similarly lead to the elevated levels of wildtype p53 protein with reduced transcriptional activity [18-20]. (3) The enhancement of HIF-1 $\alpha$ mRNA by triptolide may be a compensatory response by the tumor cells in an effort to maintain HIF-1 $\alpha$ transcriptional activity. Or, subsequent to its RNA Pol II inhibition, the transcription of some factor(s) responsible for degrading HIF-1 $\alpha$ mRNA may be arrested, finally disrupting the degradation machinery and resulting in the accumulation of HIF- $1 \alpha$ mRNA. This is potentially similar to the effect of actinomycin $\mathrm{D}$, an inhibitor of transcription, on the degradation of HIF-1 $\alpha$ protein. Actinomycin D was found to lead to super-induction of HIF- $1 \alpha$ protein by inhibiting the transcription of some unidentified factor(s) responsible for degrading HIF-1 $\alpha$ protein (transcription-dependent degradation) [39]. (4) Triptolide could be used as a tool compound to probe the potential new function of HIF-1 $\alpha$ protein due to its unique action. (5) The interference of triptolide with HIF-1 $\alpha$ is one of its possible anticancer and/or antiangiogenesis mechanisms.

Those points obviously deserve further investigation. Hypoxia is prevalent in solid tumors and HIF-1 $\alpha$ is a critical regulator of tumor hypoxia adaption [40]. Clarification of the conditions or stimulations required for specific HIF-1 $\alpha$ activities (for instance, promoting or suppressing the expression of specific genes or gene sets) may greatly help the development of HIF-1 $\alpha$-targeted therapeutics and the monitor of cancer progression and prognosis. Moreover, demonstration of the function(s) of HIF-1 $\alpha$ in addition to its transcriptional activity, if any indeed as shown in this study, will give new insights into hypoxia biology. On the other hand, triptolide is a promising anticancer lead compound and its chemical modifications are actively ongoing [14,41]. The discovery of its unique impact on HIF-1 $\alpha$ suggests another possible anticancer mechanism. Therefore, the questions of how triptolide increases the levels of HIF$1 \alpha$ mRNA, why and how it reduces the transcriptional activity of HIF-1 $\alpha$ protein need thoroughly elucidating.

\section{Conclusions}

In summary, triptolide was found to increase the levels of HIF- $1 \alpha$ mRNA and protein and to reduce HIF- $1 \alpha$ transcriptional activity, which contributes to its antitumor effect partially. These data, on one hand, propose a new potential anticancer mechanism of triptolide, and stress a possibility that HIF-1 $\alpha$ functions in an unresolved nature or condition on the other.

\section{Methods}

\section{Chemicals}

Triptolide used in our experiments was prepared from tripterygium wilfordii Hook $\mathrm{F}$ with the following procedure. First, the powder of tripterygium wilfordii bark was extracted with ethanol to obtain its ethanol extracts. The ethanol extracts were next extracted with chloroform to get chloroform extracts. Then, we purified the chloroform extracts on silica gel columns with a mobile phase of chloroform to get triptolide crude. Finally, by recrystalizing the triptolide crude with ether, we obtained triptolide with the HPLC purity of more than 99\%. MG132 was purchased from Sigma (St. Louise, MO, USA). All the compounds were dissolved at $10 \mathrm{mM}$ in dimethyl sulfoxide (Sigma, St. Louise, MO, USA) as stock solution. The stock solutions were kept in aliquot at $-20^{\circ} \mathrm{C}$ (triptolide) or at $-80^{\circ} \mathrm{C}$ (MG132) and thawed immediately prior to each experiment.

\section{Cell culture}

Human ovarian SKOV-3, lung A549, breast MCF-7 and prostate DU145 cancer cells were obtained from the American Type Culture Collection (Manassas, VA, USA). Cells were cultured in DMEM (SKOV-3 and MCF-7), F12 (A549), or RPIM-1640 medium (DU145) (Life Technologies, Grand Island, NY USA) supplemented with 15\% FBS (Life Technologies, Grand Island, NY, USA) at $37^{\circ} \mathrm{C}$ in a humidified atmosphere containing $5 \%$ $\mathrm{CO}_{2}$. Hypoxia treatment was performed by placing cells in a $\mathrm{CO}_{2}$ Water Jacketed Incubator (Thermo Forma, Model 3110 series, $\mathrm{OH}$, USA) flushed with a mixture of $1 \% \mathrm{O}_{2}, 5 \% \mathrm{CO}_{2}$ and $94 \% \mathrm{~N}_{2}$.

\section{Cytotoxicity assays}

The cytotoxicity of triptolide was examined by sulforhodamine B (SRB) assays as described previously [42]. Briefly, cells in 96-well plates were treated in triplicate with gradient concentrations of triptolide at $37^{\circ} \mathrm{C}$ for $72 \mathrm{~h}$, and then assessed with SRB (Sigma, St. Louise, MO, USA). The absorbance at $560 \mathrm{nM}$ was detected with a plate reader (SpectraMax, Molecular Devices, CA, USA). The growth inhibition rate was calculated as $\left(1-\mathrm{A}_{560}\right.$ treated $/ \mathrm{A}_{560}$ control $) \times 100 \%$.

\section{Western blotting analyses}

Cells were lyzed in $1 \times$ SDS lysis buffer [50 mM Tris$\mathrm{HCl}$ (pH6.8), $100 \mathrm{mM}$ DTT, 2\% SDS, 0.1\% bromphenol blue, $10 \%$ glycerol] and then boiled for $10-15 \mathrm{~min}$. Western blotting analyses were performed as previously described [43] using appropriate antibodies including anti-HIF-1 $\alpha$ (BD, Franklin Lakes, NJ, USA), anti-HIF-1 $\beta$ (BD, Franklin Lakes, NJ, USA), anti-HIF-2 $\alpha$ (R\&D Systems, MN, USA), anti- $\beta$-actin (Beyotime, Haimen, China), and the levels of cellular proteins were visualized with peroxidase-coupled secondary antibodies (Dingguo, Beijing, China) using ECL-plus kit from Amersham Biosciences (Buckinghamshire, UK). 


\section{Cell immunofluorescence}

Immunofluorescence analyses were performed as described previously [27]. Briefly, Cells $\left(0.5 \times 10^{5}\right)$ were seeded onto cover slips in 24-well plates and exposed to hypoxia for $12 \mathrm{~h}$ treated with or without triptolide simultaneously. One slip was left at normoxia as control. Then, the cells were fixed, washed, permeabilized, washed and blocked. After that, the cells were sequentially incubated with anti-HIF- $1 \alpha$ antibody (BD, Franklin Lakes, NJ), washed, and incubated with Alexa Fluor 488-conjugated anti-mouse secondary antibody (Invitrogen, Carlsbad, CA). Finally, the cover slips were photographed with a Leica TCS SP2 confocal microscope (Leica, Wetzlar, Germany).

\section{Co-immunoprecipitation}

Cells treated with $150 \mu \mathrm{M} \mathrm{CoCl}{ }_{2}$ with or without $1000 \mathrm{nM}$ triptolide for $12 \mathrm{~h}$ were collected for co-immunoprecipitation. Briefly, cells were lyzed with NP40 lysis buffer (Beyotime, Haimen, China) for co-immunoprecipitation. Followed by centrifugation, the supernatants were pre-cleared with $20 \mu \mathrm{L}$ protein $\mathrm{G}$ agarose beads (Beyotime, Haimen, China) coupled with mouse or rabbit IgG for over $2 \mathrm{~h}$; and then were exposed to $20 \mu \mathrm{L}$ protein $\mathrm{G}$ agarose beads coupled with the indicated antibodies for over $6 \mathrm{~h}$. The beads were washed 3 times with $1 \mathrm{~mL}$ PBS for $20 \mathrm{~min}$ each. The precipitants were dissolved with the SDS loading buffer for Western blotting analyses.

\section{Assays for proteasome activity}

The activity of $26 \mathrm{~S}$ proteasome was determined as described previously [44]. Briefly, cells were harvested and washed with PBS ( $\mathrm{pH}$ 7.4), pelleted by centrifugation and then lyzed in Lysis buffer ( $\mathrm{pH} 7.5)$ [50 mM Hepes, $5 \mathrm{mM}$ EDTA, $150 \mathrm{mM} \mathrm{NaCl}$, and $1 \%$ Triton] on ice for $30 \mathrm{~min}$. After that, whole cell lysates were centrifugated at $12000 \times \mathrm{g}$ and $4{ }^{\circ} \mathrm{C}$ for $10 \mathrm{~min}$. The supernatants were aspirated. The reaction buffer $(\mathrm{pH} 8)$ contained $20 \mathrm{mM}$ HEPES, $0.5 \mathrm{mM}$ EDTA, and $0.035 \%$ SDS. Reaction mixtures in a total volume of $100 \mu \mathrm{L}$ including reaction buffer $(85 \mu \mathrm{L})$, cell extracts $(5 \mu \mathrm{L})$, and the fluorogenic proteasome substrate Z-LLL-AMC $(10 \mu \mathrm{L})$ (Calbiochem, La Jolla, CA) were incubated at $37^{\circ} \mathrm{C}$ for $1 \mathrm{~h}$. For cell-free assays (the cell lysates were treated with triptolide), triptolide was added into the mixtures. For cellular assays (Cells were treated with triptolide and then subjected to lysis), the protein concentration was determined by the Micro BCA protocol (Pierce, Rockford, USA) and added the cell extracts with the same protein concentration into the mixtures. Cleavage activity was monitored continuously by detecting free 7-amido-4-methylcoumarin with a fluorescence plate reader (Gemini, Molecular Devices, USA) at 380/
$460 \mathrm{~nm}$. As controls for drug studies, Z-LLL-AMC was incubated with drugs in Reaction buffer without cell extracts and measurements of proteasome activity were corrected when necessary.

\section{Luciferase activity assays}

For luciferase activity assays, cells were co-transfected with 60 ng HRE luciferase reporter plasmid and renilla luciferase reporter vector pGL-3 per well using Lipofectamine ${ }^{\text {tw }} 2000$ for $24 \mathrm{~h}$. Cells were treated with triptolide for further $12 \mathrm{~h}$ and harvested for the luciferase activity analyses using the dual luciferase reporter assay system (Beyotime, Haimen, China). Luminence was measured with GloMax 96 Microplate LuminometerW/Dual injectors (Promega, Madison, USA). The firefly luciferase luminescence activity was normalized to the control renilla luciferase activity.

\section{Reverse transcription-PCR analyses}

Cells were treated with triptolide for the indicated time. Total RNA was isolated with the Trizol reagent. Total RNA was reverse transcribed using Superscript $t^{\text {tw }} I I I$ reverse transcriptase and cDNA was used for PCR with the following primers (synthesized by Sanggon Corporation, Shanghai, China): $\beta$-actin, 5'-TGA CGG GGT CAC CCA CAC TGT GCC CAT CTA-3'(forward), 5'-CTA GAA GCA TTG CGG TCG ACG ATG GAG GG3'(backward); and HIF-1 $\alpha, 5$ '-CTC AAA GTC GGA CAG CCT CA-3'(forward), 5'-CCC TGC AGT AGG TTT CTG CT-3'(backward). Amplification was done for 35 cycles, each with denaturation at $94^{\circ} \mathrm{C}$ for $1 \mathrm{~min}$, annealing at $55^{\circ} \mathrm{C}$ for $1 \mathrm{~min}$ and extension at $72^{\circ} \mathrm{C}$ for $1 \mathrm{~min}$. The products were analyzed using agarose gel electrophoresis and visualized by ethidium bromide staining.

\section{Real time-PCR Analyses}

Cells were lyzed with the Trizol reagent and total RNA was isolated with chloroform and isopropyl alcohol. One-microgram RNA was subjected to reverse transcription with the RT reagent kit (TaKaRa, Dalian, China) according to the manufacturer's instructions. Then the cDNA was amplified by Real-time PCR with the SYBR PrimeScript RT-PCR kit (Takara, Dalian, China) with the following primers (synthesized by Sanggon Corporation, Shanghai, China): $\beta$-actin, 5'-TGA CGG GGT CAC CCA CAC TGT GCC CAT CTA3'(forward), 5'-CTA GAA GCA TTG CGG TCG ACG ATG GAG GG-3'(backward); HIF-1 $\alpha, 5$ '-CTC AAA GTC GGA CAG CCT CA-3'(forward), 5'-CCC TGC AGT AGG TTT CTG CT-3'(backward); CAIX[31], 5'-CTT GGA AGA AAT CGC TGA GG-3'(forward), 5'-TGG AAG TAG CGG CTG AAG TC-3' (backward); BNIP3[31], 5'-TGC TGC TCT CTC ATT TGC TG-3' (forward), 5'-GAC TCC AGT TCT TCA TCA AAA 
GGT-3'(backward); and VEGF[31], 5'-CTA CCT CCA CCA TGC CAA GT-3'(forward), 5'-CCA CTT CGT GAT GAT TCT GC-3'(backward). The alteration of mRNA expression in cells treated with or without triptolide was assessed by delta delta $C_{t}$ method [45].

\section{ELISA assays for VEGF secretion}

The amount of secreted VEGF was tested as described previously [46]. The medium was replaced with $1.5 \mathrm{~mL} /$ well of fresh medium, and the cells were subjected to hypoxia or normoxia in the presence or absence of triptolide at the indicated concentrations for $12 \mathrm{~h}$. Then, the cell supernatants were collected, clarified by centrifugation at $1,000 \mathrm{~g}$ for $5 \mathrm{~min}$, and stored at $-20^{\circ} \mathrm{C}$. VEGF in the supernatant was determined with a VEGFELISA kit according to the manufacturer's instructions (Jingmei Biotech Co, Beijing, China). Results were normalized to the cell number.

\section{Small interfering RNA (siRNA) transfection}

siRNAs (HIF- $1 \alpha$ siRNA-1 targeting 5'-CUG AUG ACC AGC AAC UUG ATT-3' [47], HIF-1 $\alpha$ siRNA-2 targeting 5' -GCU CAA UUU AUG AAU AUU ATT-3', HIF$1 \alpha$ siRNA-3 targeting 5'-GAA GGA ACC UGA UGC UUU ATT-3' and GFP (scrambled) siRNA targeting 5'-GAC CCG CGC CGA GGU GAA GTT-3') were obtained from GenePharma (Shanghai, China). The transfection with siRNA was conducted with Lipofectamine RNAimax (Invitrogen, Carlsbad, CA) according to the manufacturer's instructions. After $24 \mathrm{~h}$, the cells were treated with or without triptolide for the indicated time.

\section{Flow cytometry}

SKOV-3 cells $\left(2 \times 10^{5}\right)$ transfected with HIF-1 $\alpha$ siRNA or GFP siRNA were seeded into 6-well plates overnight and then treated with or without triptolide for $36 \mathrm{~h}$. Apoptosis was analyzed by flow cytometry [48]. The sub-G1 cells were considered as apoptotic cells.

\section{Rat aortic ring assays}

Rat aortic ring assays were performed as described before [49]. The aortas were harvested from 6-week-old-aged Sprague-Dawley rats. Each aorta was cut into 1-mm slices and embedded in $30 \mu \mathrm{L}$ Matrigel in 24-well plates. The aortic rings were then fed with $500 \mu \mathrm{L}$ of M199 medium (10\% FCS) with different concentrations of triptolide or the solvent control. After $5-\mathrm{d}$ incubation at $37^{\circ} \mathrm{C}$ in a $\mathrm{CO}_{2}$ incubator, each aorta was photographed.

\section{Data Analyses}

Data were presented as mean $\pm \mathrm{SD}$, and differences were considered significant when $\mathrm{P}<0.05$ as determined by Student's $t$ test.

\section{Acknowledgements}

This study was supported by the grants from the National Natural Science Foundation of China (NSFC) (No.30721005 and No. 81025020), the National Science \& Technology Major Project "Key New Drug Creation and Manufacturing Program" of China (No.2009ZX09301-001), the State Key Laboratory of Drug Research (No.SIMM0912QN-02) and National Basic Research Program of China (No 2010CB934000), respectively. We thank Dr. Giovanni Melillo of the Tumor Hypoxia Laboratory, National Cancer Institute at Frederick, USA for the kind gift of the HRE luciferase reporter plasmid. We also thank Mrs. Li-Juan Lu, Mr. Yong Xi and Miss Yan-Yan Shen for their technical supports.

\section{Author details}

'Division of Antitumor Pharmacology, State Key Laboratory of Drug Research, Shanghai Institute of Materia Medica, Chinese Academy of Sciences, Shanghai 201203, China. ${ }^{2}$ Department of Medicinal Chemistry, State Key Laboratory of Drug Research, Shanghai Institute of Materia Medica, Chinese Academy of Sciences, Shanghai 201203, China. ${ }^{3}$ Department of Medical Oncology, Cancer Hospital, Shanghai Medical School, Fudan University, Shanghai 200032, China. ${ }^{4}$ Department of Pharmacology, Shenyang Pharmaceutical University, 103 Wenhua Road, Shenhe District, Shenyang 110016, China.

\section{Authors' contributions}

ZLZ, ZGL, JD and ZHM designed the study; ZLZ, ZGL, BY, YJ, YC, JMF, MD and LTT performed experiments; ZLZ, JD and ZHM analyzed data; ZL and $Y C L$ extracted and purified triptolide, tested its purity and wrote the chemical section. ZLZ and ZHM wrote the paper. All authors read and approved the final manuscript.

\section{Competing interests}

The authors declare that they have no competing interests.

Received: 26 January 2010 Accepted: 11 October 2010 Published: 11 October 2010

\section{References}

1. Marin-Hernandez A, Gallardo-Perez JC, Ralph SJ, Rodriguez-Enriquez S, Moreno-Sanchez R: HIF-1alpha modulates energy metabolism in cancer cells by inducing over-expression of specific glycolytic isoforms. Mini Rev Med Chem 2009, 9:1084-1101.

2. Rankin EB, Giaccia AJ: The role of hypoxia-inducible factors in tumorigenesis. Cell Death Differ 2008, 15:678-685.

3. Harris AL: Hypoxia-a key regulatory factor in tumour growth. Nat Rev Cancer 2002, 2:38-47.

4. Zhong H, Chiles K, Feldser D, Laughner E, Hanrahan C, Georgescu MM, Simons JW, Semenza GL: Modulation of hypoxia-inducible factor 1alpha expression by the epidermal growth factor/phosphatidylinositol 3-kinase/PTEN/AKT/FRAP pathway in human prostate cancer cells: implications for tumor angiogenesis and therapeutics. Cancer Res 2000, 60:1541-1545

5. Bos R, Zhong H, Hanrahan CF, Mommers EC, Semenza GL, Pinedo HM, Abeloff MD, Simons JW, van Diest PJ, van der Wall E: Levels of hypoxiainducible factor-1 alpha during breast carcinogenesis. J Natl Cancer Inst 2001, 93:309-314.

6. Poon E, Harris AL, Ashcroft M: Targeting the hypoxia-inducible factor (HIF) pathway in cancer. Expert Rev Mol Med 2009, 11:e26.

7. Carmeliet $P$, Dor $Y$, Herbert JM, Fukumura D, Brusselmans $K$, Dewerchin $M$, Neeman M, Bono F, Abramovitch R, Maxwell P, Koch CJ, Ratcliffe P, Moons L, Jain RK, Collen D, Keshert E: Role of HIF-1alpha in hypoxiamediated apoptosis, cell proliferation and tumour angiogenesis. Nature 1998, 394:485-490.

8. Su D, Song Y, Li R: [Comparative clinical study of rheumatoid arthritis treated by triptolide and an ethyl acetate extract of Tripterygium wilfordii]. Zhong Xi Yi Jie He Za Zhi 1990, 10:144-146, 131.

9. Yang SX, Gao HL, Xie SS, Zhang WR, Long ZZ: Immunosuppression of triptolide and its effect on skin allograft survival. Int I Immunopharmacol 1992, 14:963-969.

10. He MF, Huang YH, Wu LW, Ge W, Shaw PC, But PP: Triptolide functions as a potent angiogenesis inhibitor. Int J Cancer 126:266-278. 
11. Zhu W, Ou Y, Li Y, Xiao R, Shu M, Zhou Y, Xie J, He S, Qiu P, Yan G: A small-molecule triptolide suppresses angiogenesis and invasion of human anaplastic thyroid carcinoma cells via down-regulation of the nuclear factor-kappa B pathway. Mol Pharmacol 2009, 75:812-819.

12. Yang $S$, Chen J, Guo Z, Xu XM, Wang L, Pei XF, Yang J, Underhill CB, Zhang $L$ : Triptolide inhibits the growth and metastasis of solid tumors. Mol Cancer Ther 2003, 2:65-72.

13. Shi $X$, Jin $Y$, Cheng C, Zhang H, Zou W, Zheng Q, Lu Z, Chen Q, Lai Y, Pan J: Triptolide inhibits Bcr-Abl transcription and induces apoptosis in STI571-resistant chronic myelogenous leukemia cells harboring T315I mutation. Clin Cancer Res 2009, 15:1686-1697.

14. Li Z, Zhou ZL, Miao ZH, Lin LP, Feng HJ, Tong LJ, Ding J, Li YC: Design and Synthesis of Novel C14-Hydroxyl Substituted Triptolide Derivatives as Potential Selective Antitumor Agents. J Med Chem 2009, 52:5115-5123.

15. Lou YJ, Jin J: Triptolide down-regulates bcr-abl expression and induces apoptosis in chronic myelogenous leukemia cells. Leuk Lymphoma 2004 45:373-376.

16. Phillips PA, Dudeja V, McCarroll JA, Borja-Cacho D, Dawra RK, Grizzle WE, Vickers SM, Saluja AK: Triptolide induces pancreatic cancer cell death via inhibition of heat shock protein 70. Cancer Res 2007, 67:9407-9416.

17. Lee KY, Park JS, Jee YK, Rosen GD: Triptolide sensitizes lung cancer cells to TNF-related apoptosis-inducing ligand (TRAIL)-induced apoptosis by inhibition of NF-kappaB activation. Exp Mol Med 2002, 34:462-468.

18. Jiang $X H$, Wong $B C$, Lin MC, Zhu GH, Kung HF, Jiang SH, Yang D, Lam SK: Functional p53 is required for triptolide-induced apoptosis and AP-1 and nuclear factor-kappaB activation in gastric cancer cells. Oncogene 2001, 20:8009-8018.

19. Kiviharju TM, Lecane PS, Sellers RG, Peehl DM: Antiproliferative and proapoptotic activities of triptolide (PG490), a natural product entering clinical trials, on primary cultures of human prostatic epithelial cells. Clin Cancer Res 2002, 8:2666-2674

20. Chang WT, Kang JJ, Lee KY, Wei K, Anderson E, Gotmare S, Ross JA, Rosen GD: Triptolide and chemotherapy cooperate in tumor cell apoptosis. A role for the p53 pathway. J Biol Chem 2001, 276:2221-2227.

21. Zhu W, He S, Li Y, Qiu P, Shu M, Ou Y, Zhou Y, Leng T, Xie J, Zheng X, $X u$ D, Su X, Yan G: Anti-angiogenic activity of triptolide in anaplastic thyroid carcinoma is mediated by targeting vascular endothelial and tumor cells. Vascul Pharmacol 2010, 52:46-54.

22. Otrock ZK, Hatoum HA, Awada AH, Ishak RS, Shamseddine Al: Hypoxiainducible factor in cancer angiogenesis: structure, regulation and clinical perspectives. Crit Rev Oncol Hematol 2009, 70:93-102.

23. Guo M, Song LP, Jiang Y, Liu W, YU Y, Chen GQ: Hypoxia-mimetic agents desferrioxamine and cobalt chloride induce leukemic cell apoptosis through different hypoxia-inducible factor-1alpha independent mechanisms. Apoptosis 2006, 11:67-77.

24. Qing G, Simon MC: Hypoxia inducible factor-2alpha: a critical mediator of aggressive tumor phenotypes. Curr Opin Genet Dev 2009, 19:60-66.

25. D'Angelo G, Duplan E, Boyer N, Vigne P, Frelin C: Hypoxia up-regulates prolyl hydroxylase activity: a feedback mechanism that limits HIF-1 responses during reoxygenation. J Biol Chem 2003, 278:38183-38187.

26. Luo W, Zhong J, Chang R, Hu H, Pandey A, Semenza GL: HSP70 and CHIP selectively mediate Ubiquitination and degradation of hypoxia-inducible factor (HIF)-1\{alpha\} but not HIF-2\{alpha\}. J Biol Chem 2010, 285:3651-3663.

27. Yu B, Miao ZH, Jiang Y, Li MH, Yang N, Li T, Ding J: c-Jun protects hypoxia-inducible factor-1alpha from degradation via its oxygendependent degradation domain in a nontranscriptional manner. Cancer Res 2009, 69:7704-7712

28. Triantafyllou A, Mylonis I, Simos G, Bonanou S, Tsakalof A: Flavonoids induce HIF-1alpha but impair its nuclear accumulation and activity. Free Radic Biol Med 2008, 44:657-670.

29. Liu YV, Semenza GL: RACK1 vs. HSP90: competition for HIF-1 alpha degradation vs. stabilization. Cell Cycle 2007, 6:656-659.

30. Wang XH, Cavell BE, Syed Alwi SS, Packham G: Inhibition of hypoxia inducible factor by phenethyl isothiocyanate. Biochem Pharmacol 2009, 78:261-272.

31. Jones DT, Pugh CW, Wigfield S, Stevens MF, Harris AL: Novel thioredoxin inhibitors paradoxically increase hypoxia-inducible factor-alpha expression but decrease functional transcriptional activity, DNA binding, and degradation. Clin Cancer Res 2006, 12:5384-5394.
32. Maynard MA, Ohh M: The role of hypoxia-inducible factors in cancer. Cell Mol Life Sci 2007, 64:2170-2180.

33. Onnis B, Rapisarda A, Melillo G: Development of HIF-1 Inhibitors for Cancer Therapy. J Cell Mol Med 2009, 13:2780-2786.

34. Brinker AM, Ma J, Lipsky PE, Raskin I: Medicinal chemistry and pharmacology of genus Tripterygium (Celastraceae). Phytochemistry 2007, 68:732-766.

35. Manolescu B, Oprea E, Busu C, Cercasov C: Natural compounds and the hypoxia-inducible factor (HIF) signalling pathway. Biochimie 2009, 91:1347-1358.

36. Tang XD, Zhou $X$, Zhou KY: Dauricine inhibits insulin-like growth factor-Iinduced hypoxia inducible factor 1alpha protein accumulation and vascular endothelial growth factor expression in human breast cancer cells. Acta Pharmacol Sin 2009, 30:605-616.

37. Vispe S, DeVries L, Creancier L, Besse J, Breand S, Hobson DJ, Svejstrup JQ, Annereau JP, Cussac D, Dumontet C, Guilbaud N, Barret JM, Bailly C: Triptolide is an inhibitor of RNA polymerase I and II-dependent transcription leading predominantly to down-regulation of short-lived mRNA. Mol Cancer Ther 2009, 8:2780-2790.

38. Leuenroth SJ, Crews CM: Triptolide-induced transcriptional arrest is associated with changes in nuclear substructure. Cancer Res 2008, 68:5257-5266

39. Demidenko ZN, Rapisarda A, Garayoa M, Giannakakou P, Melillo G, Blagosklonny MV: Accumulation of hypoxia-inducible factor-1alpha is limited by transcription-dependent depletion. Oncogene 2005, 24:4829-4838.

40. Weidemann A, Johnson RS: Biology of HIF-1alpha. Cell Death Differ 2008 , 15:621-627.

41. Aoyagi $Y$, Hitotsuyanagi $Y$, Hasuda T, Matsuyama S, Fukaya H, Takeya K, Aiyama R, Matsuzaki T, Hashimoto S: Fluorination of triptolide and its analogues and their cytotoxicity. Bioorg Med Chem Lett 2008, 18:2459-2463.

42. Li W, Shao Y, Hu L, Zhang X, Chen Y, Tong L, Li C, Shen X, Ding J: BM6, a new semi-synthetic vinca alkaloid, exhibits its potent in vivo anti-tumor activities via its high binding affinity for tubulin and improved pharmacokinetic profiles. Cancer Biol Ther 2007, 6:787-794.

43. Tao Z, Zhou Y, Lu J, Duan W, Qin Y, He X, Lin L, Ding J: Caspase-8 preferentially senses the apoptosis-inducing action of NG-18, a Gambogic acid derivative, in human leukemia HL-60 cells. Cancer Biol Ther 2007, 6:691-696.

44. Hong SH, Kim J, Kim JM, Lee SY, Shin DS, Son KH, Han DC, Sung YK, Kwon BM: Apoptosis induction of 2'-hydroxycinnamaldehyde as a proteasome inhibitor is associated with ER stress and mitochondrial perturbation in cancer cells. Biochem Pharmacol 2007, 74:557-565.

45. Livak KJ, Schmittgen TD: Analysis of relative gene expression data using real-time quantitative PCR and the 2(-Delta Delta C(T)) Method. Methods 2001, 25:402-408.

46. Dai M, Miao ZH, Ren X, Tong LJ, Yang N, Li T, Lin LP, Shen YM, Ding J: MFTZ-1 reduces constitutive and inducible HIF-1alpha accumulation and VEGF secretion independent of its topoisomerase II inhibition. J Cell Mol Med 2009.

47. Sowter HM, Raval RR, Moore JW, Ratcliffe PJ, Harris AL: Predominant role of hypoxia-inducible transcription factor (Hif)-1alpha versus Hif-2alpha in regulation of the transcriptional response to hypoxia. Cancer Res 2003, 63:6130-6134.

48. Feng JM, Zhu H, Zhang XW, Ding J, Miao ZH: Proteasome-dependent degradation of Chk1 kinase induced by the topoisomerase II inhibitor R16 contributes to its anticancer activity. Cancer Biol Ther 2008, 7:1726-1731.

49. Sun QM, Miao ZH, Lin LP, Gui M, Zhu CH, Xie H, Duan WH, Ding J: BB, a new EGFR inhibitor, exhibits prominent anti-angiogenesis and antitumor activities. Cancer Biol Ther 2009, 8:1640-1647.

doi:10.1186/1476-4598-9-268

Cite this article as: Zhou et al:: Increased accumulation of hypoxiainducible factor-1 $1 \alpha \alpha$ with reduced transcriptional activity mediates the antitumor effect of triptolide. Molecular Cancer 2010 9:268. 